\title{
Segmentectomy for selected cT1N0M0 non-small cell lung cancer: A prospective study at a single institute
}

\author{
Hiroaki Nomori, PhD, ${ }^{\text {a }}$ Takeshi Mori, $\mathrm{PhD},{ }^{\mathrm{b}}$ Koei Ikeda, $\mathrm{PhD},{ }^{\mathrm{b}}$ Kentaro Yoshimoto, $\mathrm{PhD},{ }^{\mathrm{b}}$ \\ Kenichi Iyama, $\mathrm{PhD},{ }^{\mathrm{c}}$ and Makoto Suzuki, $\mathrm{PhD}^{\mathrm{b}}$
}

Background: To examine whether segmentectomy is radical for cT1N0M0 non-small cell lung cancer (NSCLC), a prospective single-arm study was performed at a single institution.

\begin{abstract}
Methods: The criteria for segmentectomy were as follows: (1) peripheral-type cT1NOM0 NSCLC; (2) intraoperative frozen sections of sentinel nodes identified with isotope showing no metastasis; (3) surgical margins greater than $2 \mathrm{~cm}$; (4) patient choice for segmentectomy; and (5) exclusion of right middle lobe tumors. From 2005 to 2009, of 245 patients with cT1N0M0 NSCLC, $195(80 \%)$ were enrolled in the present study. Of these 195 patients, 179 ultimately underwent segmentectomy with systematic lymph node dissection. Of these 179 patients, $134(75 \%)$ had tumors $2 \mathrm{~cm}$ or smaller, and $45(25 \%)$ had tumors $2.1 \mathrm{~cm}$ to $3 \mathrm{~cm}$. The median follow-up period was 43 months.
\end{abstract}

Results: All 181 tumors from 179 patients were stage pN0. Of the 179 patients, 6 developed distant site recurrence and 3 local recurrence (ie, 1 developed pulmonary metastases within the same lobe 21 months after segmentectomy and 2 developed local recurrence at the surgical margin 60 and 62 months after segmentectomy, respectively). The 5-year overall survival was $94 \%$ for patients with tumors $2 \mathrm{~cm}$ or smaller and $81 \%$ for those with $2.1-\mathrm{cm}$ to $3-\mathrm{cm}$ tumors. Postoperative pulmonary function was preserved at $90 \% \pm 12 \%$ of preoperative levels.

Conclusions: Segmentectomy with systematic lymph node dissection with a sufficient surgical margin could be a radical treatment for selected cT1N0M0/pNO NSCLC while preserving pulmonary function. The surgical margin should be monitored for the development of local recurrence for a long period after segmentectomy. (J Thorac Cardiovasc Surg 2012;144:87-93)

Earn CME credits at

http://cme.ctsnetjournals.org

Recent advances in radical and anatomic pulmonary segmentectomy are going to change the surgical procedures for clinical T1N0M0 non-small cell lung cancer (NSCLC). ${ }^{1}$ Although the Lung Cancer Study Group, from the results of a prospective randomized controlled trial of sublobar resection vs lobectomy for clinical stage T1N0M0 NSCLC, concluded that the former was inferior to the latter owing to greater local recurrence and poorer survival, ${ }^{2}$ several recent retrospective studies have shown

\footnotetext{
From the Division of General Thoracic Surgery, ${ }^{\text {a }}$ Keio University School of Medicine, Tokyo, Japan; and Departments of Thoracic Surgery ${ }^{\mathrm{b}}$ and Pathology, ${ }^{\mathrm{c}}$ Kumamoto University Graduate School of Medical Sciences, Kumamoto, Japan.

Disclosures: Authors have nothing to disclose with regard to commercial support.

Received for publication Oct 30, 2011; revisions received Feb 29, 2012; accepted for publication March 16, 2012; available ahead of print April 16, 2012.

Address for reprints: Hiroaki Nomori, MD, PhD, Division of General Thoracic Surgery, Department of Surgery, Keio University School of Medicine, 35 Shinanomachi, Shinjuku-ku, Tokyo 160-8582, Japan (E-mail: hnomori@qk9.so-net.ne.jp). $0022-5223 / \$ 36.00$

Copyright (c) 2012 by The American Association for Thoracic Surgery doi:10.1016/j.jtcvs.2012.03.034
}

a similar prognosis between lobectomy and segmentectomy in patients with cT1N0M0 NSCLCs. ${ }^{3-5}$ However, the radicality of segmentectomy remains controversial owing to the variability of patient selection by each surgeon.

On the basis of our hypothesis that radical segmentectomy could play a role in local control for T1N0M0 NSCLC, as well as does lobectomy, provided that sufficient lymph node dissection was conducted, we began a prospective study of segmentectomy with our own criteria for patients with cT1N0M0 NSCLC at Kumamoto University Hospital in $2005 .{ }^{6}$ For radical segmentectomy, we dissected the hilar mediastinal lymph nodes to the extent possible and examined them to identify the sentinel node (SN) using radioisotopes. ${ }^{7,8}$ When the intraoperative frozen SN sections indicated metastasis or the surgical margin was insufficient, we usually conducted completion lobectomy. Therefore, the radical segmentectomy described in the present study should be distinguished from simple segmentectomy by the extent of lymph node dissection. It seems similar to the "radical lobectomy" proposed by Cahan" in 1960, when pneumonectomy was the standard procedure. Cahan ${ }^{9}$ defined radical lobectomy as an operation in which 1 or 2 lobes were excised in a block dissection with their regional hilar and mediastinal lymph nodes. After his proposal, lobectomy with mediastinal lymph node dissection replaced 


\section{Abbreviations and Acronyms \\ DFS = disease-free survival \\ $\mathrm{FEV}_{1}=$ forced expiratory volume in 1 second \\ NSCLC $=$ non-small cell lung cancer \\ OS = overall survival \\ $\mathrm{SN}=$ sentinel node}

pneumonectomy, even for stage $\mathrm{N} 1$ or $\mathrm{N} 2$ disease, and this technique has been established as the standard procedure for NSCLC to date.

In the present study, to prove our hypothesis, we examined the long-term prognosis, recurrence pattern, and pulmonary function after radical segmentectomy in patients with cT1NOM0/pN0 NSCLC.

\section{METHODS \\ Eligibility}

The ethics committees of Kumamoto University approved the study protocol for segmentectomy using radioisotopes for SN identification in patients with cT1NOM0 NSCLC. Clinical staging was performed by body computed tomography scanning, brain magnetic resonance imaging, and fluorodeoxyglucose-positron emission tomography. Lymph node biopsy using endobronchial ultrasonography was conducted for swelling lymph nodes, and mediastinoscopy was not undertaken. All patients provided informed consent after fully discussing the risks and benefits with their surgeons. The inclusion criteria of segmentectomy were as follows: (1) cT1N0M0 peripheral-type NSCLC; (2) a single lesion in 1 lobe; (3) intraoperative pleural lavage cytology showing no malignancy; (4) SN intraoperative frozen section showing no metastasis; and (5) patient choice for segmentectomy instead of lobectomy after informed consent. The exclusion criteria were tumors within the right middle lobe and patients unable to tolerate segmentectomy.

\section{Patients}

From April 2005 to March 2009, 245 patients with clinical stage T1NOM0 NSCLC were referred to the Department of Thoracic Surgery of Kumamoto University Hospital for surgical treatment (Figure 1). Of these, segmentectomy was planned for 195 patients $(80 \%)$ according to the criteria described, 30 patients $(12 \%)$ underwent lobectomy, and 20 $(8 \%)$ underwent wedge resection. The reasons for conducting lobectomy in the 30 patients were determined by our criteria as follows: (1) right middle lobe tumors in 15 patients; (2) multiple lesions in the same lobe in 7; (3) centrally located tumors in 5; and (4) patient request for lobectomy in 3. The reasons for conducting wedge resection in 20 patients were intolerance to segmentectomy in 19 (forced expiratory volume in 1 second [FEV 1 ] $<50 \%$ in 8 patients, severe comorbidities in 8 , and old age in 3 ) and patient request for wedge resection by the remaining patient. Of the 195 patients scheduled for segmentectomy, 148 (76\%) underwent SN identification using technetium-99m tin colloid or technetium-99m phytate, and 47 patients did not (pure ground-glass opacity findings on computed tomography in 41 patients and old age in 6).

\section{SN Identification}

SNs were identified to target the nodes submitted for intraoperative frozen section analysis but not to reduce the extent of lymph node dissection. Administration of radiotracers was done using a previously reported method. ${ }^{10-14}$ The identified SNs were used for intraoperative frozen

\section{Flow of participants through the trial}

\begin{tabular}{|c|c|}
\hline \multicolumn{2}{|c|}{245 patients with cT1NOMO NSCLC } \\
\hline & $\begin{array}{l}\text { 50: Excluded } \\
\text { 30: Lobectomy } \\
\text { 15: Right middle lobe } \\
\text { 7: Multiple lesions in the sar } \\
\text { 5: Centrally located tumor } \\
\text { 3: Patient's request } \\
\text { 20: Wedge resection } \\
\text { 19: Poor risk } \\
\text { 1: Patient's request }\end{array}$ \\
\hline \multicolumn{2}{|c|}{ 195: Enrolled in study } \\
\hline & $\begin{array}{l}\text { 16:Drop out } \\
\text { 14: Completion lobectomy } \\
\text { 7: SN metastasis } \\
\text { 7: Insufficient margin } \\
\text { 1: Positive in washing cytology } \\
\text { 1: Pleural dissemination }\end{array}$ \\
\hline
\end{tabular}

FIGURE 1. Treatment flow chart. NSCLC, Non-small cell lung cancer.

section analysis with hematoxylin and eosin staining. The lymph node nomenclature and tumor stage were according to the Staging Manual in Thoracic Oncology by the International Association for the Study of Lung Cancer in 2009. ${ }^{15}$

\section{Nomenclature of Segments}

The nomenclature of pulmonary segments was defined as follows: the apical, dorsal, and ventral segment of the right upper lobe was S1, S2, and S3, respectively; the apicodorsal, ventral, lingular superior, and lingular inferior of the left upper lobe was S1+S2, S3, S4, and S5, respectively; the superior, mediobasal, ventrobasal, lateral basal, and dorsobasal of the lower lobe was S6, S7, S8, S9, and S10, respectively.

TABLE 1. Patient characteristics for planning segmentectomy

\begin{tabular}{lc}
\hline \multicolumn{1}{c}{ Characteristic } & Value \\
\hline Age $(\mathrm{y})$ & \\
Mean & $66 \pm 10$ \\
Range & $29-83$ \\
Gender & \\
Male & 97 \\
Female & 98 \\
Preoperative pulmonary function & \\
FEV $/$ FVC $(\%)$ & \\
Mean & $73 \pm 10$ \\
Range & $38-94$ \\
\%FEV & \\
Mean & $109 \pm 21$ \\
Range & $49-180$ \\
\hline$F E V_{l}$. Forced expiratory volume in 1 second $F V C$, forced vital capacity.
\end{tabular}

$F E V_{l}$, Forced expiratory volume in 1 second; $F V C$, forced vital capacity. 
TABLE 2. Patients with metastasis in sentinel nodes diagnosed by intraoperative frozen section analysis

\begin{tabular}{|c|c|c|c|c|c|c|}
\hline Pt. no. & Age (y)/gender & Histologic type & Planned segmentectomy & SN with metastasis & Procedure & pTNM stag \\
\hline 1 & $72 / \mathrm{M}$ & Adenocarcinoma & Right S6 & 11 & Lobectomy & T1aN1M0 \\
\hline 2 & $54 / \mathrm{F}$ & Adenocarcinoma & Left $S 9+$ S10 & 12 & Lobectomy & $\mathrm{T} 2 \mathrm{aN} 2 \mathrm{M} 0$ \\
\hline 3 & $50 / \mathrm{F}$ & Adenocarcinoma & Left $\mathrm{S} 1+\mathrm{S} 2+\mathrm{S} 3$ & 5,10 & Lobectomy & $\mathrm{T} 1 \mathrm{bN} 2 \mathrm{M} 0$ \\
\hline 4 & $69 \mathrm{~F}$ & Adenocarcinoma & Left $\mathrm{S} 1-\mathrm{S} 3$ & 5 & Lobectomy & $\mathrm{T} 2 \mathrm{aN} 2 \mathrm{M} 0$ \\
\hline 5 & 73/M & SCC & Left $\mathrm{S} 1+2$ & 5 & Lobectomy & T1aN2M0 \\
\hline 6 & $80 / \mathrm{M}$ & Adenocarcinoma & Left $\mathrm{S} 1+\mathrm{S} 2$ & 5 & Left $\mathrm{S} 1+\mathrm{S} 2+\mathrm{S} 3$ & $\mathrm{~T} 1 \mathrm{bN} 2 \mathrm{M} 0$ \\
\hline 7 & $81 / \mathrm{M}$ & Adenocarcinoma & Left S4+S5 & 5 & Left S4+S5 & T1aN2M0 \\
\hline
\end{tabular}

Pt. no., Patient number; $S N$, sentinel node; $M$, male; $F$, female; $S C C$, squamous cell carcinoma.

\section{Operative Procedures}

Immediately after thoracotomy, the surface of the visceral pleura over the tumor was irrigated with a jet stream of saline solution using a $20-\mathrm{mL}$ syringe and the fluid collected for cytologic analysis. Under thoracotomy, segmentectomy with systematic lymph node dissection was performed as reported previously.$^{6-8}$ The hilar nodal stations were completely dissected with taping of segmental vessels and bronchi. After lymph node dissection, the SNs were examined by intraoperative frozen section analysis. The sections were serially cut at about $3 \mathrm{~mm}$ thickness. If the SN could not be identified because of low radioactivity in the nodes, the number 10 to 13 nodes and lobe-specific mediastinal nodes were submitted for frozen section analysis. When frozen section analysis of SN demonstrated metastasis, completion lobectomy was performed. During surgery, the surgical margin was confirmed to be sufficiently greater than $2 \mathrm{~cm}$ or the maximum diameter of the tumor. If the surgical margin was insufficient on the cut surface of the specimens, completion lobectomy was performed.

\section{Pulmonary Function Test}

The vital capacity, forced vital capacity, and $\mathrm{FEV}_{1}$ were measured in the seated position using a dry rolling-seal spirometer (CHESTAC-9800DN; Chest, Tokyo, Japan) in accordance with the American Thoracic Society standards. ${ }^{16}$ Preoperative pulmonary function was measured within 1 month before surgery, and postoperative function was measured at least 6 months after surgery (median, 6 months; range, 6-17 months). Preand postoperative pulmonary function was measured in $169(94 \%)$ of the 179 patients.

\section{Pathologic Diagnosis}

Formalin-fixed surgical specimens were processed by routine hematoxylin and eosin staining and elastica van Gieson staining. The histologic subtypes were classified according to the World Health Organization classification. ${ }^{17}$

\section{Postoperative Follow-up}

All patients were followed up every 3 to 6 months after surgery until 5 years postoperatively and yearly thereafter. The follow-up period ranged from 5 to 74 months, with an average and median period of 43 months.

\section{Statistical Analysis}

A chi-square test or $t$-test was used for intergroup comparisons. Survival was estimated using the Kaplan-Meier method, ${ }^{18}$ and differences in survival between the tumor groups were determined using log-rank analysis. The survival period from the date of segmentectomy to the date of the last follow-up examination or death was used for the estimation. Disease-free survival (DFS) was the interval from segmentectomy to proven detection of recurrence, death, or the last follow-up visit. Death caused by other disease was included as an event in the analysis of DFS. Univariate and multivariate Cox proportional hazards regression models were used to compare the groups and generate the hazard ratios and $95 \%$ confidence intervals. Multivariate models were adjusted for age, gender, tumor size, histologic type, and pleural invasion. Values of $P<.05$ were accepted as indicating statistical significance.

\section{RESULTS}

The characteristics of the 195 patients who were scheduled for segmentectomy are listed in Table 1 . Of these patients, 3 had a $\% \mathrm{FEV}_{1}$ less than $60 \%$.

Of the 195 patients scheduled for segmentectomy, 7 were diagnosed with lymph node metastasis according to the findings from intraoperative frozen section analysis of the SN (Table 2). Of these 7 patients, 5 underwent completion lobectomy, and 2 underwent segmentectomy because of their old age (patients 6 and 7). Another 7 patients with an insufficient surgical margin with segmentectomy underwent completion lobectomy (Table 3). One patient demonstrated positive pleural lavage cytology and therefore underwent lobectomy. Another patient underwent completion exploratory thoracotomy, owing to tumor pleural dissemination. Thus, 179 patients were ultimately treated by segmentectomy alone (Figure 1). Two patients had double cT1NOM0 NSCLCs located in different lobes that were treated by segmentectomy of each lobe, resulting in a total of 181 tumors.

TABLE 3. Patients undergoing completion lobectomy because of insufficient surgical margins

\begin{tabular}{|c|c|c|c|c|c|c|}
\hline Pt. no. & Age (y)/Gender & Histologic type & Tumor size $(\mathbf{c m})$ & Planned segmentectomy & Converted procedure & pTNM stage \\
\hline 1 & $52 / \mathrm{M}$ & Adenocarcinoma & 1.3 & Left $\mathrm{S} 1+\mathrm{S} 2$ & Lobectomy & T1aNOM0 \\
\hline 2 & $60 / \mathrm{M}$ & Adenocarcinoma & 1.4 & Right $\mathrm{S} 1+\mathrm{S} 2$ & Lobectomy & T1aN0M0 \\
\hline 3 & 73/M & Adenocarcinoma & 1.7 & Left S6 & Lobectomy & T1aN0M0 \\
\hline 4 & $53 / \mathrm{M}$ & BAC & 1.8 & Right S6 & Lobectomy & T1aN0M0 \\
\hline 5 & $71 / \mathrm{M}$ & SCC & 2.0 & Left $S 6 b+S 8 a+S 9 a$ & Lobectomy & T1aNOM0 \\
\hline 6 & $68 / \mathrm{F}$ & Adenocarcinoma & 2.3 & Right S3 & Lobectomy & T1bNOM0 \\
\hline 7 & $80 / \mathrm{M}$ & BAC & 2.5 & Right $\mathrm{S} 3+\mathrm{S} 2 \mathrm{~b}$ & Lobectomy & T1bN0M0 \\
\hline
\end{tabular}

Pt. no., Patient number; $M$, male; $B A C$, bronchioloalveolar carcinoma; $S C C$, squamous cell carcinoma; $F$, female. 
TABLE 4. Characteristics of tumors treated by segmentectomy

\begin{tabular}{|c|c|c|c|}
\hline \multirow[b]{2}{*}{ Characteristic } & \multicolumn{2}{|c|}{ Tumor size (cm) } & \multirow[b]{2}{*}{ Total } \\
\hline & $\leq \mathbf{2}$ & 2.1-3 & \\
\hline Mean tumor size $(\mathrm{cm})$ & $1.4 \pm 0.4$ & $2.5 \pm 0.3$ & $1.7 \pm 0.6$ \\
\hline \multicolumn{4}{|l|}{ Tumor location } \\
\hline Right upper lobe & 43 & 14 & 57 \\
\hline Right lower lobe & 35 & 9 & 44 \\
\hline Left upper lobe & 40 & 17 & 57 \\
\hline Left lower lobe & 16 & 5 & 21 \\
\hline Right upper and lower lobes & 1 & 0 & 1 \\
\hline Right upper and left lower lobes & 1 & 0 & 1 \\
\hline \multicolumn{4}{|l|}{ Resected segments (n) } \\
\hline Mean & $1.6 \pm 0.6$ & $1.5 \pm 0.6$ & $1.5 \pm 0.6$ \\
\hline Range & $1-4$ & $1-4$ & $1-4$ \\
\hline \multicolumn{4}{|l|}{ Histologic type } \\
\hline Adenocarcinoma & 51 & 25 & 76 \\
\hline Bronchioloalveolar carcinoma & $77 *$ & 8 & 85 \\
\hline Squamous cell carcinoma & 6 & 10 & 16 \\
\hline Adenosquamous carcinoma & 2 & 2 & 4 \\
\hline \multicolumn{4}{|l|}{ Pathologic stage } \\
\hline T1NOM0 & 131 & 39 & 170 \\
\hline T2NOM0 & 5 & 6 & 11 \\
\hline Total (n) & 136 & 45 & 181 \\
\hline
\end{tabular}

*Significant difference between the 2 groups $(P<.001)$.

The characteristics of the 181 tumors in 179 patients ultimately treated by segmentectomy are listed in Table 4 . Of the 181 tumors, $136(75 \%)$ were $2 \mathrm{~cm}$ or less in size and 45 $(25 \%)$ were $2.1 \mathrm{~cm}$ to $3 \mathrm{~cm}$. The distribution of tumorcontaining lobes and the number of resected segments did not differ between those $2 \mathrm{~cm}$ or less and those $2.1 \mathrm{~cm}$ to $3 \mathrm{~cm}$. The histologic type was adenocarcinoma in 76, bronchioloalveolar carcinoma (BAC) in 85, squamous cell carcinoma in 16, and adenosquamous carcinoma in 4 . Of the 136 tumors $2 \mathrm{~cm}$ or less, $77(57 \%)$ were BAC, a significantly greater rate than the 8 BACs $(18 \%)$ in the 45 tumors $2.1 \mathrm{~cm}-3 \mathrm{~cm}$ in size $(P<.001)$. Of the 136 tumors $2 \mathrm{~cm}$ or less, $6(4 \%)$ were squamous cell carcinoma, a significantly lower rate than the 10 squamous cell carcinoma $(22 \%)$ of the 45 tumors $2.1 \mathrm{~cm}$ to $3 \mathrm{~cm}$ in size $(P<.001)$. The pathologic tumor stage was T1N0M0 in 170 tumors and T2N0M0 because of visceral pleural invasion (p1-p3) in 11 .

No operative mortality occurred in 179 patients. The chest tube was removed within a mean of $2.1 \pm 2.8$ days (median, 2 days; range, 1-29 days) after segmentectomy. Three patients developed prolonged postoperative air leakage of more than 7 days. Postoperative pneumonia occurred in 1 patient with diabetes mellitus and low $\mathrm{FEV}_{1}$ /forced vital capacity (48\%), who was discharged from the hospital after recovery. No other major morbidity was observed.

The 9 patients had recurrence after segmentectomy (Table 5). Six patients (patients 1-6) presented with their first recurrence at distant sites and 3 (patients 7-9) at local sites. The site of local recurrence in the 3 patients was pulmonary metastases ( 2 lesions) within the same lobe in 1 patient (patient 7) and the surgical margin in 2 (patients 8 and 9). The pulmonary metastases within the same lobe in the former patient occurred 21 months after segmentectomy. The local recurrence at the surgical margin in the latter 2 patients occurred 60 and 62 months after segmentectomy, respectively; the histologic type of the primary tumor was adenocarcinoma with a BAC pattern. These 3 patients with local recurrence also underwent completion lobectomy, resulting in subsequent diseasefree recovery. Five patients died with other diseases. Thus, 165 patients have been healthy without disease since segmentectomy.

Figure 2 shows the overall survival (OS) and DFS. The 5 -year OS and DFS of all 179 patients was $91 \%$ and $91 \%$, respectively (Figure 2, $A$ and $B$ ). The 5-year OS of the BAC $(\mathrm{n}=84)$ and non-BAC cases $(\mathrm{n}=95)$ was $97 \%$ and $86 \%$, respectively, a significant difference $(P=.04$; Figure $2, C)$. The 5-year DFS of BAC and non-BAC cases $(97 \%$ and $85 \%$, respectively) was also significantly different $(P=.006$; Figure 2, $D)$. The 5-year OS of tumors $2.0 \mathrm{~cm}$ or less and $2.1 \mathrm{~cm}$ to $3.0 \mathrm{~cm}$ in size was $94 \%$ and $81 \%$, respectively, a significant difference $(P=.006$; Figure $2, E)$. The 5-year DFS of tumors $2.0 \mathrm{~cm}$ or less and $2.1 \mathrm{~cm}$ to 3.0 $\mathrm{cm}$ in size $(95 \%$ and $79 \%$, respectively) also differed

TABLE 5. Characteristics of patients who developed recurrence after segmentectomy

\begin{tabular}{|c|c|c|c|c|c|c|c|}
\hline Pt. no. & Age/gender & Histologic type & Size $(\mathbf{c m})$ & pTNM stage & Procedure & Recurrence site (time) & Prognosis (time) \\
\hline 1 & 79/M & SCC & 1.8 & T1aNOM0 & Right S6 & $\mathrm{LN}^{*}(9 \mathrm{~m})$ & Dead $(13 \mathrm{~m})$ \\
\hline 2 & $63 / \mathrm{M}$ & SCC & 2.5 & T1bN0M0 & Right S1 & Pleura (7 m) & Dead (22 m) \\
\hline 3 & 78/M & SCC & 2.5 & T1bN0M0 & Left $\mathrm{S} 1+\mathrm{S} 2$ & Liver (15 m) & Dead (27 m) \\
\hline 4 & $70 / \mathrm{F}$ & SCC & 2.2 & T1bN0M0 & Right S6 & Bilateral lung (40 m) & Dead (43 m) \\
\hline 5 & $77 / \mathrm{F}$ & Adenocarcinoma & 1.4 & T1aN0M0 & Right S3 & Bilateral lung $(10 \mathrm{~m})$ & Alive (57 m) \\
\hline 6 & $80 / \mathrm{F}$ & $\mathrm{SCC}$ & 2.5 & T1bN0M0 & Left $\mathrm{S} 1+\mathrm{S} 2$ & $\mathrm{SCN}+$ bilateral lung $(10 \mathrm{~m})$ & Alive $(53 \mathrm{~m})$ \\
\hline 7 & $70 / \mathrm{F}$ & Adenocarcinoma & 2.0 & T1aNOM0 & Right $\mathrm{S} 1+\mathrm{S} 2$ & Lung $\dagger(21 \mathrm{~m})$ & Alive (42 m) \\
\hline 8 & 76/M & Adenocarcinoma & 2.0 & T1aN0M0 & Left S3 & Surgical margin $(60 \mathrm{~m})$ & Alive (64 m) \\
\hline 9 & $65 / \mathrm{M}$ & Adenocarcinoma & 2.4 & T1bN0M0 & Right $S 3+S 2 b$ & Surgical margin $(62 \mathrm{~m})$ & Alive (64 m) \\
\hline
\end{tabular}

Pt. no., Patient number; $M$, male; $S C C$, squamous cell carcinoma; $L N$, lymph node; $F$, female; $S C N$, supraclavicular lymph node. *Bilateral mediastinal and hilar lymph nodes. $\dagger$ Same lobe. 
A

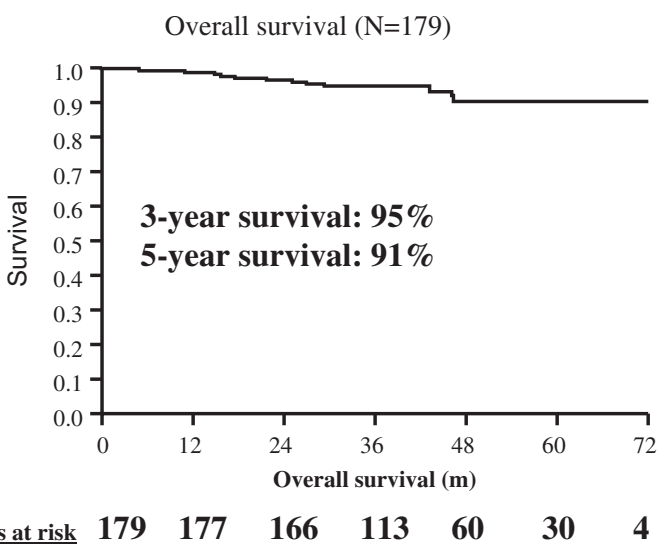

B

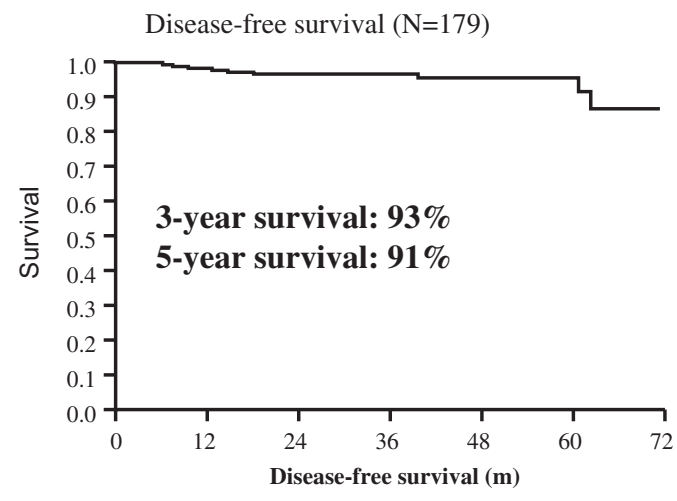

$\begin{array}{llllllll}\text { Patients at risk } & 179 & 175 & 163 & 111 & 59 & 30 & 4\end{array}$

C

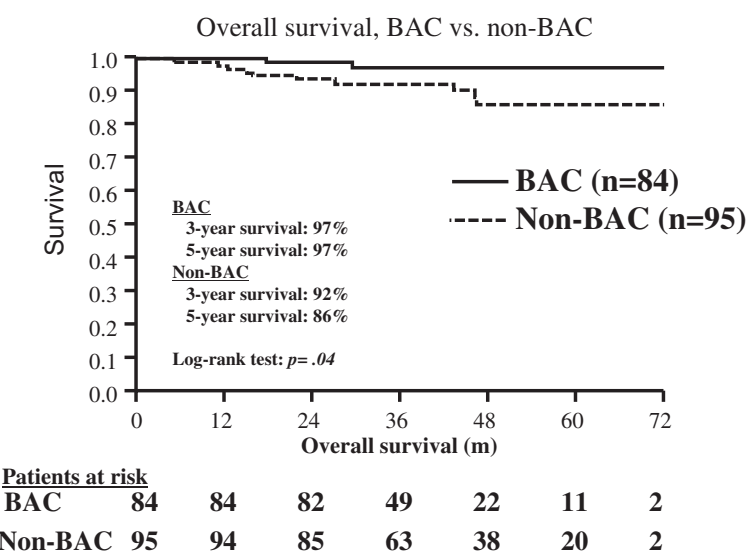

D

Disease-free survival, BAC vs. non-BAC

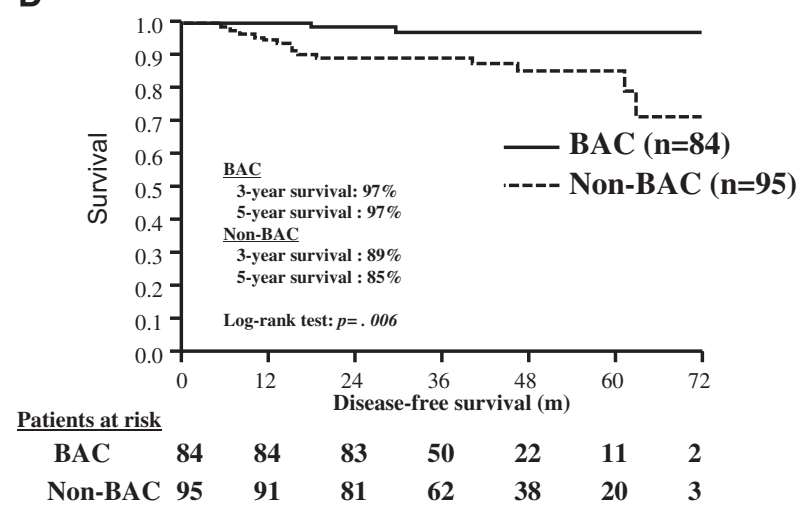

E

Overall survival, $\leq \mathbf{2} \mathrm{cm} \quad$ vs. $\mathbf{2 . 1 - 3} \mathrm{cm}$

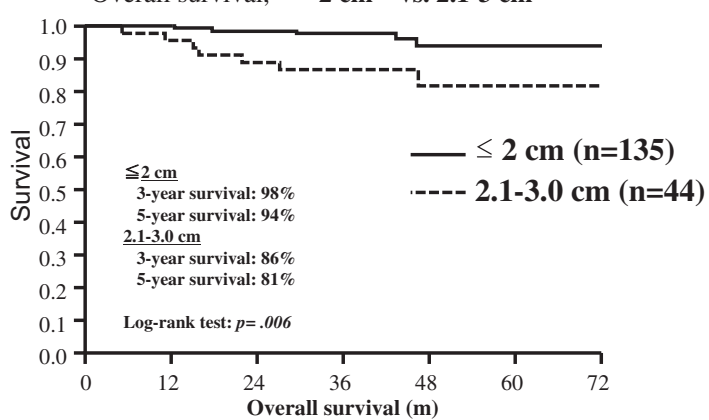

Patients at risk

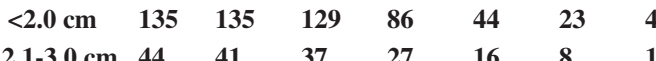

$\mathbf{F}$

Disease-free survival, $\leq \mathbf{2}$ cm vs. $\mathbf{2 . 1 - 3} \mathbf{c m}$

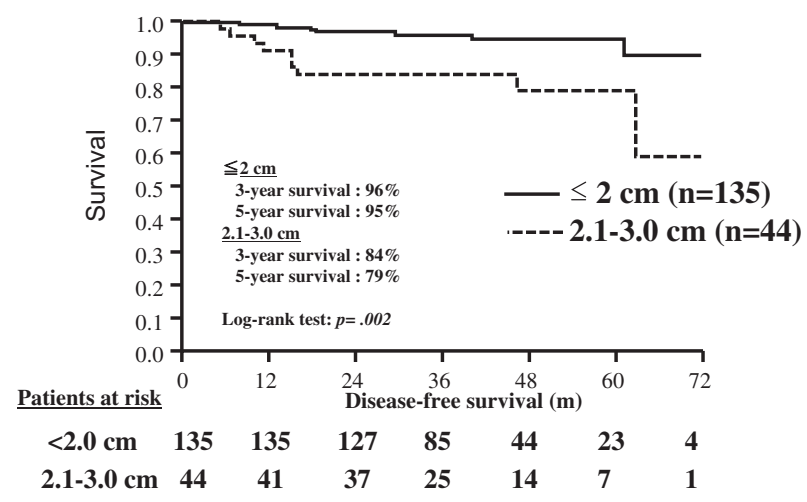

FIGURE 2. A, Overall survival $(O S)$ for all total patients. B, Disease-free survival $(D F S)$ for all patients. C, OS for those with bronchioloalveolar carcinoma $(B A C)$ and non-BAC. D, DFS for those with BAC carcinoma and non-BAC. E, OS for those with tumors $2 \mathrm{~cm}$ or less and $2.1 \mathrm{~cm}$ to $3 \mathrm{~cm}$. F, DFS for those with tumors $2 \mathrm{~cm}$ or less and $2.1 \mathrm{~cm}$ to $3 \mathrm{~cm}$.

significantly $(P=.002$; Figure $2, F)$. The 5 -year DFS of male and female patients $(86 \%$ and $95 \%$, respectively) also differed significantly $(P=.04)$. The 5-year DFS of patients with stage p0 tumors and $1-\mathrm{p} 3$ tumors $(93 \%$ and $63 \%$, respectively) also differed significantly $(P=.04)$. No significant difference was found in the 5-year DFS between patients with 65 years old or younger and older than 65 years ( $96 \%$ and $86 \%$, respectively, $P=.11)$.
The results of the multivariate analysis of DFS for gender, age, tumor size, histologic type, and pleural invasion are listed in Table 6; none reached statistical significance.

The mean postoperative $\mathrm{FEV}_{1} /$ preoperative $\mathrm{FEV}_{1}$ was $90 \% \pm 12 \%$ (Figure 3 ). Regarding the number of resected segments, 96 patients were treated by resection of 1 segment, 65 patients by 1.5 or 2 segments, and 10 patients by 
TABLE 6. Multivariate analysis of disease-free survival for gender, age, tumor size, histologic type, and pleural invasion

\begin{tabular}{lcc}
\hline \multicolumn{1}{c}{ Variable } & Hazard ratio & $\boldsymbol{P}$ value \\
\hline Gender (male vs female) & 2.26 & .16 \\
Age $(>65$ vs $\leq 65 \mathrm{y})$ & 2.48 & .10 \\
Tumor size $(2-3$ vs $\leq 2 \mathrm{~cm})$ & 2.64 & .08 \\
Histologic type (non-BAC vs BAC) & 3.71 & .07 \\
Pleural invasion (p1-p3 vs p0) & 1.24 & .75 \\
\hline
\end{tabular}

$B A C$, Bronchioloalveolar carcinoma.

more than 2.5 segments. The corresponding postoperative $\mathrm{FEV}_{1} /$ preoperative $\mathrm{FEV}_{1}$ values of these patient groups were $90 \% \pm 10 \%, 89 \% \pm 13 \%$, and $87 \% \pm 10 \%$, with no significant differences among the 3 groups.

\section{DISCUSSION}

The results of the present study highlight the following points. First, the prognosis after segmentectomy was not inferior to that generally reported after lobectomy. Second, $\mathrm{SN}$ identification was useful for intraoperative $\mathrm{N}$ staging. Third, although 3 patients developed local recurrences, none developed recurrence at the regional lymph nodes. Fourth, postoperative pulmonary function was preserved at approximately $90 \%$ of the preoperative levels. Finally, preservation of postoperative pulmonary function did not differ according to the number of resected segments.

In the present study, the 5-year OS after segmentectomy was $91 \%$, similar to that previously reported after lobectomy in patients with stage IA NSCLC. ${ }^{3-5,19}$ One of the most remarkable findings of the present study was that local recurrence developed in only 3 patients $(1.7 \%)$ and none of the patients developed recurrence in the regional lymph nodes, which could be the result of our extended lymph node dissection and intraoperative $\mathrm{N}$-staging using SN identification.

In the present study, SNs were identified using radioisotopes for intraoperative $\mathrm{N}$-staging. However, we do not consider $\mathrm{SN}$ identification to be always necessary during segmentectomy. If $\mathrm{SN}$ identification is not used during segmentectomy, in principle, all the dissected lymph nodes should be submitted for frozen section analysis in its place, because the frequency of lymph node metastasis in cT1N0M0 NSCLC has been reported be approximately $10 \%$ according to the Japanese Lung Cancer Registry from 2004. ${ }^{19}$ However, intraoperative frozen examination of all dissected lymph nodes is not usually available. Therefore, when not using SN identification, we recommend the following methods to target lymph nodes submitted for frozen section analysis during segmentectomy. First, in the hilar lymph nodes, nodes 12 and 13, at least, should be submitted for frozen section analysis, rather than node 10 or 11 , because our previous study indicated that the rate of nodes 12 and 13 being a SN was $39 \%$ and $57 \%$, respectively, and that of nodes 10 and 11 was only $10 \%$ and $16 \%$,

\section{Preservation of pulmonary function}

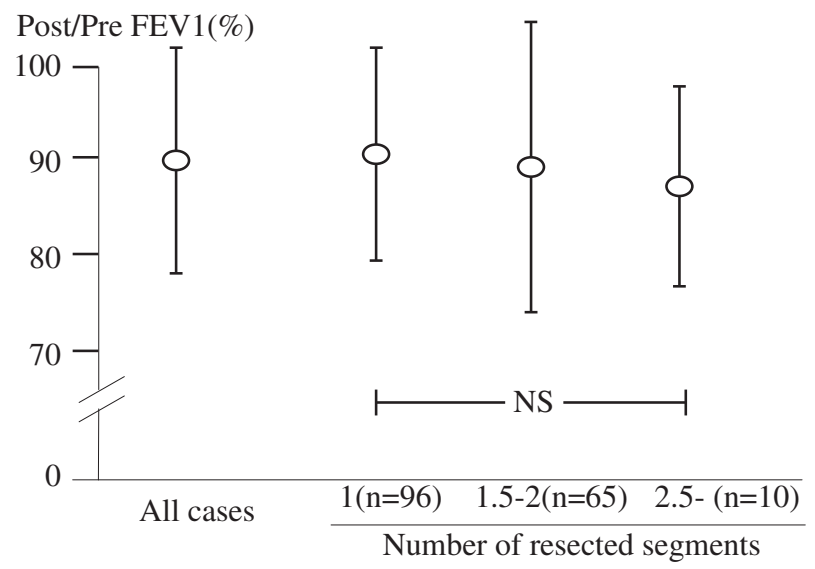

FIGURE 3. Preservation of pulmonary function. $F E V_{l}$, Forced expiratory volume in 1 second; $N S$, not significant.

respectively. ${ }^{11}$ Second, in the mediastinal nodes, the lobespecific nodes should be submitted for frozen section analysis.

In the 2 patients who developed local recurrence at the surgical margin, the primary tumors of both patients were histologically typed as adenocarcinoma demonstrating a BAC pattern at the periphery. These recurrences developed more than 5 years after segmentectomy. Although the surgical margins on the resected specimens at segmentectomy in both patients had been confirmed as sufficient on the formalin-fixed sections, their recurrence might have been caused by BAC spreading at the other margins, resulting in recurrence long after surgery. Segmentectomy in these 2 patients was conducted within the first year after the beginning of the study, which might have still represented a learning curve for radical segmentectomy. Since 2 years after beginning the study, we have used a ring-shaped forceps $3 \mathrm{~cm}$ to $5 \mathrm{~cm}$ in diameter to grasp the whole tumor, followed by cutting lung tissue away from the forceps. We believe that this technique is useful for taking a sufficient surgical margin during segmentectomy.

Even with extensive lymph node dissection and sufficient surgical margins during segmentectomy, pulmonary metastasis within the same lobe can be missed. In the present study, 1 patient developed pulmonary metastases within the same lobe after segmentectomy. However, the recent development of high-resolution computed tomography can identify pulmonary lesions even $0.2 \mathrm{~cm}$ in size, which could lead to the correct indication for segmentectomy.

Postoperative pulmonary function after segmentectomy was preserved at approximately $90 \%$ of the preoperative values in the present study, similar to the data reported by several investigators. ${ }^{20-22}$ We previously examined the preservation of pulmonary function in each lobe treated by segmentectomy using perfusion scanning with single 
photon emission computed tomography, which indicated a significant decrease after resection of multiple segments compared with resection of a single segment. ${ }^{23}$ However, the present study, which measured overall pulmonary function using routine pulmonary function testing, showed no significant difference according to the number of resected segments.

To date, several investigators have reported the outcomes of sublobar resection for cT1N0M0 $2 \mathrm{~cm}$ or less in size. ${ }^{3-5}$ For cT1NOM0 NSCLC tumors $2.1 \mathrm{~cm}$ to $3 \mathrm{~cm}$ in size, the indication of segmentectomy has been controversial. In comparing the outcomes between segmentectomy and lobectomy for tumors $2.1 \mathrm{~cm}$ to $3 \mathrm{~cm}$, Okumura and colleagues $^{24}$ reported the former to be inferior to the latter, but Okada and colleagues ${ }^{25}$ found no difference between the 2 procedures. The present study demonstrated the 5 -year OS and DFS of tumors $2.1 \mathrm{~cm}$ to $3 \mathrm{~cm}$ to be $81 \%$ and $79 \%$, respectively, similar to the Japanese Lung Cancer Registry data from 2004, in which most patients were treated by lobectomy. We, therefore, believe that segmentectomy could be indicated for pT1NOMO NSCLC even for tumors $2.1 \mathrm{~cm}$ to $3 \mathrm{~cm}$ in size, provided that extended lymph node dissection is performed and a sufficient surgical margin is taken.

Although the univariate analysis showed the significance of DFS for gender, tumor size, histologic type, and pleural invasion, multivariate analysis showed any significance for none of these factors, which could be caused by few events $(\mathrm{n}=16)$ in the present study. We believe that a massive study in the future will show the significance of DFS for these factors, all well-known significant prognostic factors for NSCLC.

The most significant limitation of the present study was that it was a nonrandomized controlled study. Therefore, we must await the outcomes of ongoing randomized controlled trials between lobectomy and sublobar resection from the United States and Japan. However, from the present study, we believe that radical segmentectomy could play a role in the local control of T1NOM0 NSCLC, as well as lobectomy, provided that a sufficient lymph node dissection was conducted.

\section{References}

1. Nomori H, Okada M. Illustrated textbook of anatomical pulmonary segmentectomy. New York: Springer-Verlag; 2012.

2. Lung Cancer Study Group, Ginsberg RH, Rubinstein LV. Randomized trial of lobectomy versus limited resection for T1N0 non-small cell lung cancer. Ann Thorac Surg. 1995;60:615-23.

3. Tsubota N, Ayabe K, Doi O, Mori T, Namikawa S, Taki T, et al. Ongoing prospective study of segmentectomy for small lung tumors. Ann Thorac Surg. 1998;66:1787-90.
4. Kodama K, Doi O, Higashiyama M, Yokouchi H. Intentional limited resection for selected patients with T1NOM0 non-small cell lung cancer. J Thorac Cardiovasc Surg. 1997;114:347-53.

5. Okada M, Koike T, Higashiyama M, Yamato Y, Kodama K, Tsubota N. Radical sublobar resection for small-sized non-small cell lung cancer: a multicenter study. J Thorac Cardiovasc Surg. 2006;132:769-75.

6. Nomori H, Ikeda K, Mori T, Kobayashi H, Iwatani K, Kawanaka K, et al. Sentinel node navigation segmentectomy for c-T1N0M0 non-small cell lung cancer. $J$ Thorac Cardiovasc Surg. 2007;133:780-5.

7. Nomori H, Ohba Y, Shibata H, Shiraishi K, Mori T, Shiraishi S. Required area of lymph node sampling during segmentectomy for clinical stage IA non-small cell lung cancer. J Thorac Cardiovasc Surg. 2010;139:38-42.

8. Nomori H, Mori T, Izumi Y, Kohno M, Yoshimoto K, Suzuki M. Is completion lobectomy merited for unanticipated nodal metastases after radical segmentectomy for cT1N0M0/pN1-2 non-small cell lung cancer? J Thorac Cardiovasc Surg. Epub 2011 Nov 19.

9. Cahan WG. Radical lobectomy. J Thorac Cardiovasc Surg. 1960;39:555-72.

10. Nomori H, Horio H, Naruke T, Orikasa H, Yamazaki K, Suemasu K. Use of technetium-99m tin colloid for sentinel lymph node identification in non-small cell lung cancer. J Thorac Cardiovasc Surg. 2002;124:486-92.

11. Nomori H, Watanabe K, Ohtsuka T, Naruke T, Suemasu K. In vivo identification of sentinel nodes for clinical stage I non-small cell lung cancer for abbreviation of mediastinal lymph node dissection. Lung Cancer. 2004;46:49-55.

12. Nomori H, Ikeda K, Mori T, Shiraishi S, Kobayashi H, Iwatani K, et al. Sentine node identification in clinical stage Ia non-small cell lung cancer by a combined single photon emission computed tomography/computed tomography system. $J$ Thorac Cardiovasc Surg. 2007;134:182-7.

13. Nomori H, Ohba Y, Yoshimoto K, Shibata H, Mori T, Shiraishi S, et al. Difference of sentinel lymph node identification between tin colloid and phytate in patients with non-small cell lung cancer. Ann Thorac Surg. 2009;87:906-10.

14. Nomori H. Sentinel node mapping in lung cancer: the Japanese experience. Semin Thorac Cardiovasc Surg. 2009;21:316-22.

15. Goldstraw P, ed. Staging Manual in Thoracic Oncology. International Union Against Cancer. Orange Park, FL: Editorial Rx Press; 2009.

16. American Thoracic Society. Standardization of spirometry-1987 update. Am Rev Respir Dis. 1987;136:1285-98.

17. Travis M, Colvy T, Corrin B, Shimosato Y, Brambilla E. World Health Organization International Histological Classification of Tumors: Histological Typing of Lung and Pleural Tumors. 3rd ed. In collaboration with Sobin LH and pathologists from 14 countries. Berlin: Springer-Verlag; 1999.

18. Kaplan EL, Meier P. Non-parametric estimation from incomplete observations. $J$ Am Stat Assoc. 1958;53:457-84

19. Sawabata N, Miyaoka E, Asamura H, Nakanishi Y, Eguchi K, Mori M, et al. Japanese Lung Cancer Registry Study of 11,663 Surgical Cases in 2004: demographic and prognosis changes over decade. J Thorac Oncol. 2011;6:1229-35.

20. Keenan RJ, Landreneau RJ, Maley RH Jr, Singh D, Macherey R, Bartley S, et al. Segmental resection spares pulmonary function in patients with stage I lung cancer. Ann Thorac Surg. 2004;78:228-33.

21. Harada H, Okada M, Sakamoto T, Matsuoka H, Tsubota N. Functional advantage after radical segmentectomy versus lobectomy for lung cancer. Ann Thorac Surg. 2005;80:2041-5.

22. Okada M, Koike T, Higashiyama M, Yamato Y, Kodama K, Tsubota N. Radica sublobar resection for small-sized non-small cell lung cancer: a multicenter study. J Thorac Cardiovasc Surg. 2006;132:769-75.

23. Yoshimoto K, Nomori H, Mori T, Kobayashi H, Ohba Y, Shibata H, et al. Quantification of the impact of segmentectomy on pulmonary function by perfusion single photon emission computed tomography and multidetector computed tomography. J Thorac Cardiovasc Surg. 2009;137:1200-5.

24. Okumura M, Goto M, Ideguchi K, Tamura M, Sasaki H, Tanaka H, et al. Factors associated with outcome of segmentectomy for non-small cell lung cancer: longterm follow-up study at a single institution in Japan. Lung Cancer. 2007;58:231-7.

25. Okada M, Nishio W, Sakamoto T, Uchino K, Yuki T, Nakagawa A, et al. Effect of tumor size on prognosis in patients with non-small cell lung cancer: the role of segmentectomy as a type of lesser resection. J Thorac Cardiovasc Surg. 2005; 129:87-93. 